
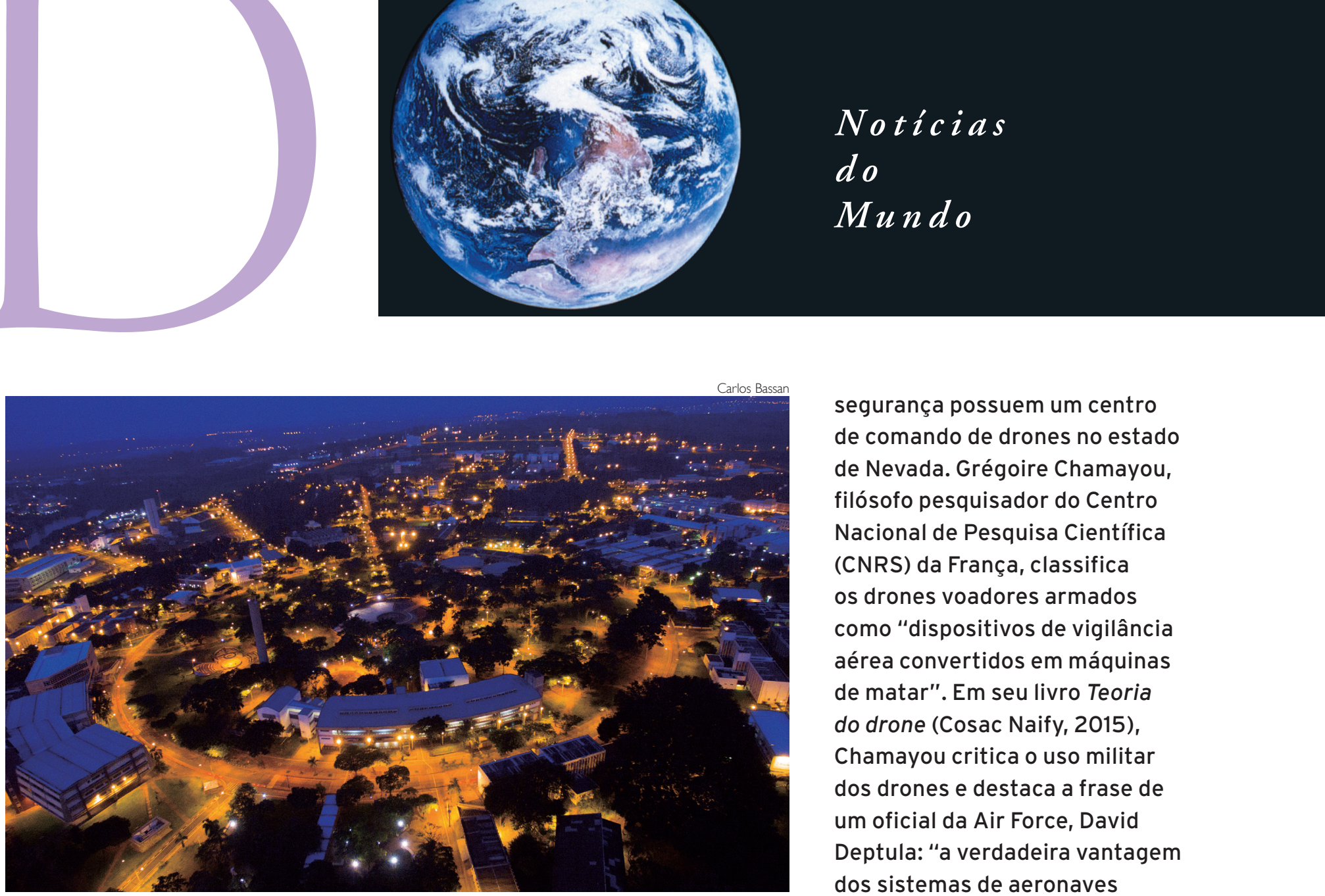

Foto do campus da Unicamp tirada com uso de drone

\title{
TECNOLOGIA
}

\section{Olhos no céu: as implicações éticas do uso de drones desafia legisladores em todo mundo}

Em abril, o filme Eye in the sky (Decisão de risco, em português) estreou nos cinemas brasileiros. Estrelado por Helen Mirren, Alan Rickman e Aaron Paul, o longa narra uma operação secreta dos governos do Reino Unido e dos Estados Unidos, que usam drones para combater terroristas no Quênia. Os agentes percebem que um atentado suicida está em curso e decidem impedi-lo eliminando os suspeitos por meio do lançamento de um míssil, com a ajuda de um drone. Mas, a entrada de uma criança no local inicia um dilema na equipe: disparar ou não o míssil? 0 debate ético por trás do uso de drones para espionar e matar também preocupa, cada vez mais, os pesquisadores.

Os drones têm ganhado os céus das cidades mundo afora. Também chamados de veículos aéreos não tripulados (VANTs), essas tecnologias têm amplo uso para fins militares, inclusive para os EUA, cujas forças de segurança possuem um centro de comando de drones no estado de Nevada. Grégoire Chamayou, filósofo pesquisador do Centro Nacional de Pesquisa Científica (CNRS) da França, classifica os drones voadores armados como "dispositivos de vigilância aérea convertidos em máquinas de matar". Em seu livro Teoria do drone (Cosac Naify, 2015), Chamayou critica o uso militar dos drones e destaca a frase de um oficial da Air Force, David Deptula: "a verdadeira vantagem dos sistemas de aeronaves não pilotadas é que permitem projetar poder sem projetar vulnerabilidade". Para ele, a ideia de "projetar poder" pode ser entendida como estender a força militar além das fronteiras. "É a questão da intervenção militar no estrangeiro (...). A preservação pelo drone se dá pela remoção do corpo vulnerável, deixando-o fora do alcance", escreve.

Eles também podem ser desarmados mas acoplados a câmeras, para uso comercial, por autoridades civis e policiais ou mesmo para recreação. Uma pesquisa recente da Administração Federal da Aviação dos EUA (FAA), que ouviu pilotos de aviões e helicópteros de voos comerciais e não comerciais, mostrou que, entre agosto de 2015 


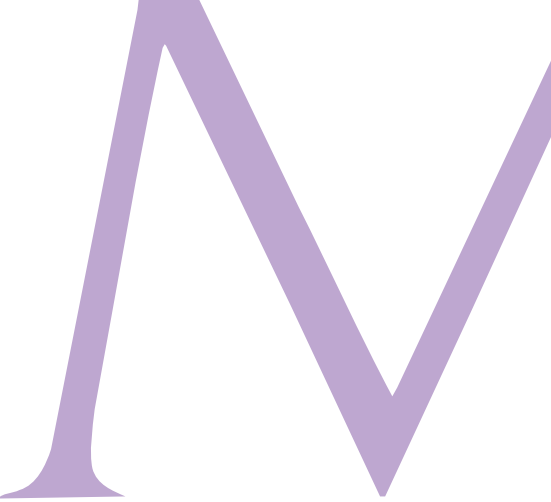

e janeiro deste ano, aconteceram 582 ocorrências relacionadas com o avistamento de drones no país. No Brasil, esses veículos têm variados tipos de uso, como em filmagens de eventos e fotografia aérea. A prefeitura de São Paulo, por sua vez, adotou drones para monitorar focos da dengue; eles também foram usados para mapear os estragos do desastre ambiental em Mariana (MG); a Força Aérea Brasileira (FAB) comprou o drone israelense Hermes 900 , com dez câmeras de alta resolução, para patrulhar áreas de grande concentração populacional durante a última Copa do Mundo.

De fato, o uso de drones no Brasil ainda está em fase de regulamentação. A Anac apresentou uma proposta de regulamento para consulta pública online, que ficou disponível até novembro de 2015. Agora, segundo o site da agência, as contribuições estão sendo analisadas e a previsão é de que a norma seja publicada até as Olimpíadas.

\section{PRIVACIDADE E USO SOCIAL DOS DRONES}

“Essa questão dos drones está quase virando um problema restrito de proteção de dados. Muitos países estão se movimentando para fazer algum tipo de regulamentação nesse sentido", avalia Danilo
Doneda, doutor em direito pela Universidade do Estado do Rio de Janeiro (Uerj) e consultor da Secretaria de Proteção ao Consumidor do Ministério da Justiça para o anteprojeto de lei sobre proteção de dados pessoais no Brasil. Ele avalia que a tendência é que esses dispositivos fiquem cada vez mais baratos e menores, o que pode dificultar sua fiscalização. Para Doneda, a tentativa da regulamentação feita pela Anac é importante, mas não está focada na questão da privacidade. “Na Argentina, por exemplo, a regulamentação de drones foi feita pela autoridade de proteção de dados, pensando na privacidade", explica. Aqui no Brasil, o anteprojeto de lei de dados pessoais, que está em tramitação na Casa Civil, pode auxiliar nesse sentido. “Qualquer coleta de dados está abrangida no texto, e o drone pode ser usado como uma tecnologia para coleta de dados pessoais. Hoje os drones são visíveis, mas vai chegar um momento em que talvez eles não o sejam", alerta.

Para o pesquisador, outra ação que precisa ser levada em conta é a da educação. “Quando uma pessoa compra um drone com uma câmera, ela precisa ser educada para saber que aquilo não pode ser utilizado para saber o que tem no quintal do vizinho, para não ver mais do que ela veria normalmente. Muito menos invadir a casa do vizinho com o drone, porque aí cometerá um delito".

0 uso que é feito de drones na questão da privacidade dos usuários também é tema do projeto \#DroneHackademy, uma academia hackativista de ciência aberta, criada pelos pesquisadores Pablo de Soto e Lot Amorós em parceria com o MediaLab.UFRJ e apoio da Rede Lavits. Uma das ações do projeto é a publicação do guia "Como e por que se proteger dos veículos aéreos não tripulados", disponível online. Segundo o guia, a experiência de ter um veículo desses sobrevoando, sem informações de quem é o piloto, qual é a natureza do voo ou mesmo qual será o destino final das imagens captadas por suas câmeras pode ser intimidante. De acordo com trecho da publicação, "o voo pode parecer especialmente violento se pairar ostensivamente a baixa altitude sobre uma propriedade privada, violando o direito à privacidade dos moradores. Os drones são ferramentas de poder e controle para os governos, forças de segurança e organizações privadas, mas agora 


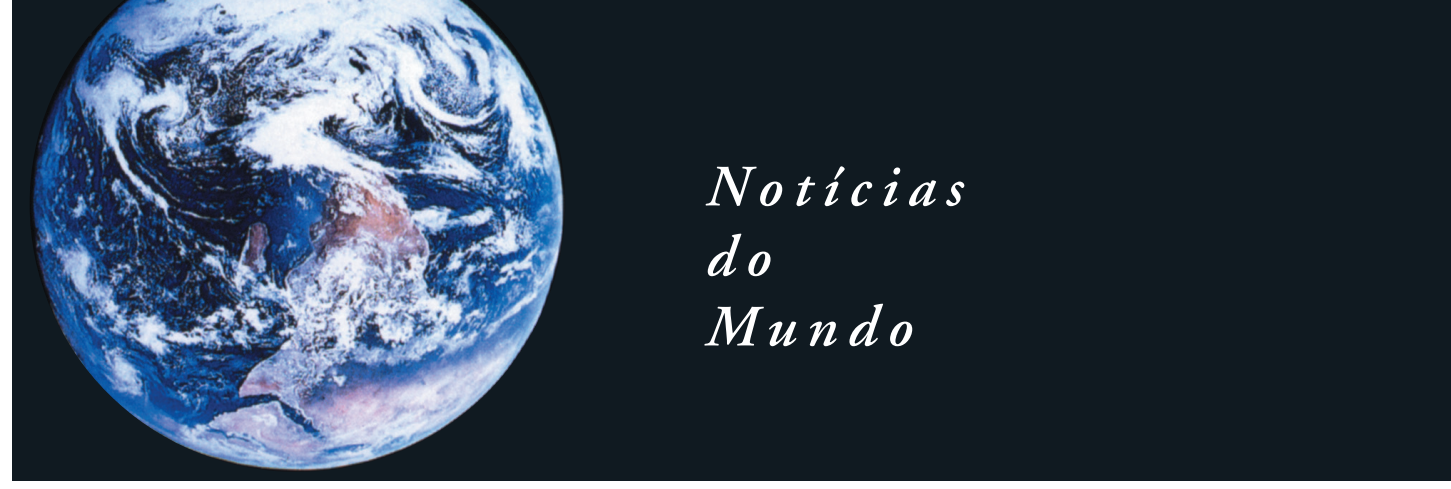

também estão ao alcance de quase qualquer indivíduo".

O guia deixa claro que não se trata de um manifesto antidrone, porque tais equipamentos podem ser úteis para a sociedade, mas traz instruções para que as pessoas saibam se defender de um eventual uso abusivo. 0 pesquisador Pablo de Soto explica, em artigo na revista Teknocultura (vol.12, no3, 2015) que a ideia do projeto é promover o uso de drones como uma tecnologia social. Para isso, suas ações envolvem, além do guia, a criação de um veículo aéreo não tripulado, batizado de Flone, construído com hardware e software livres, e a realização de uma cartografia aérea da Vila Autódromo, uma comunidade local do Rio de Janeiro que resiste à expulsão em uma área anexa à construção do Parque Olímpico.

Falar sobre drones e pensar sobre sua utilização, a se julgar pelos números, se mostra cada vez mais necessário. Se a projeção da Admistração Federal dos Estados Unidos (AFA) se concretizar, até 2020 serão sete milhões de drones voando somente pelos céus do país. De acordo com a agência Lusa, será o triplo do número que se espera estar em circulação no final de 2016.

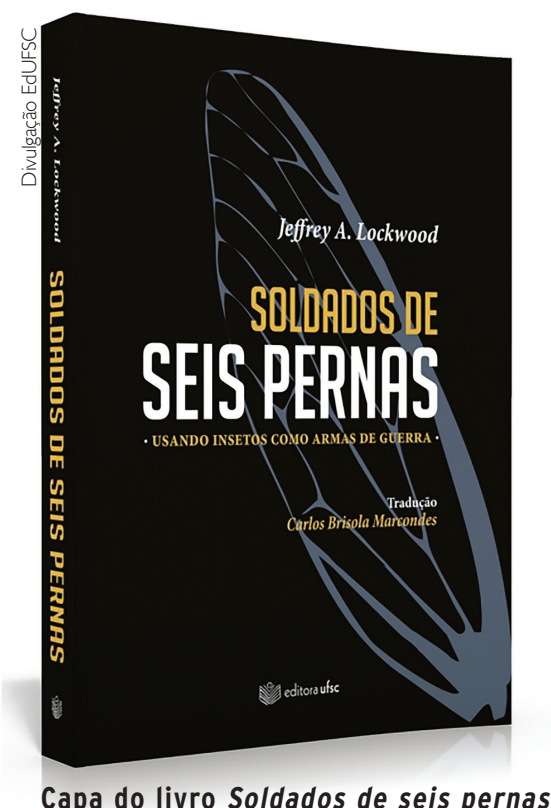

RESENHA

\section{Soldados de seis pernas}

Jáimaginou umabombadeabelhas? $\mathrm{Ou}$ insetos criados especialmente para disseminar doenças? Ou ainda pragas controladas para destruir plantações de nações inimigas? De acordo com Jeffrey Lockwood, entomólogo e professor do Departamento de Ciências Naturais e Humanidades da Universidade do Wyoming, Estados Unidos, isso não é apenas imaginação, mas uma assustadora realidade. Em seu livro Soldados de seis pernas: usando insetos como armas de guerra, ele conta a história ainda pouco conhecida da utilização de insetos como armas de guerra e instrumentos de tortura e terror. Publicado originalmente pela Oxford University Press e lançado no Brasil no ano passado pela Editora da Universidade Federal de Santa Catarina (EdUFSC), o livro já recebeu dois prêmios literários: a Medalha John Burroughs e o Pushcart Prize.

Lockwood analisou de forma exaustiva documentos históricos e arquivos militares em busca de material para compor seu livro. $\mathrm{O}$ resultado é um relato bem documentado e assombroso sobre como simples insetos podem se tornar verdadeiras armas de destruição.

ARMAS DE GUERRA Insetos são utilizados como arma há séculos. O relato de Soldados de seis pernas começa no paleolítico e chega aos dias atuais. Os primeiros registros de guerras narram a utilização de abelhas e vespas para desorientar exércitos inimigos. Na Idade Média, exércitos catapultavam colmeias de abelhas sobre os muros de cidades cercadas. Em 1942, bombardeiros japoneses lançaram recipientes de cerâmica cheios de vetores de cólera sobre cidades no sul da China, fazendo mais de 200 mil vítimas. Em 1960, estrategistas norte-americanos produziram mensalmente 130 milhôes de mosquitos portadores do flavivírus com o objetivo de disseminar a febre 